Vol. 37(2), pp. 125-136, Dec. 2018

ISSN 1821-536X (print)

ISSN 2619-8789 (electronic)
Tanzania Journal of Engineering and Technology

Copyright (c) 2018 College of Engineering and

Technology, University of Dar es Salaam

Full Length Research Paper

Creative commons licence type $C C B Y-N C-N D$

\title{
Low voltage ride through enhancement for wind turbines equipped with DFIG under symmetrical grid faults
}

\author{
Jackson J. Justo and Francis A. Mwasilu* \\ Department of Electrical Engineering, University of Dar es Salaam, P.O. Box 35136, \\ Dar es Salaam, Tanzania. \\ *Correspondent Email: fmwasilu@yahoo.co.uk
}

\begin{abstract}
In modern power systems with significant penetration of wind-turbines (WTs), improvement of low voltage ride through (LVRT) capability of WTs equipped with doubly-fed induction generators (DFIGs) is an important issue. Thus, this paper proposes a low voltage ride through (LVRT) strategy, which comprise of a capacitor connected in series with an inductor both connected in parallel to a resistor. The configuration is then connected to a small series resistor via a pair of antiparallel-Thyristors. The circuit and its switching control scheme of the proposed LVRT circuit are designed to: minimize the transition times, maintain the RSC connection to the rotor-windings, and reduce oscillations of dc-link voltage. In this case, the capacitor is entitled to eliminate ripples generated in the rotor voltage while the inductor reduces the ripple in rotor current. Different fault conditions were studied to validate the performance of the proposed scheme using MATLAB/Simulink platform. Comparative results and analysis are presented with conventional LVRT strategies.
\end{abstract}

Keywords: Doubly-Fed Induction Generator (DFIG), Fault Ride Through (FRT), Low Voltage Ride Through (LVRT), Rotor Side Converter (RSC), and Wind Turbines (WTs).

\section{INTRODUCTION}

The ever-growing global energy demand has stimulated the move for efficient utilization of the available renewable energy resources (RER) in recent decades. Wind power is among the alternative RER entitled to replace the fossil energy in the near future. This has led to increase in the development of new power generators technologies for wind turbine (WT) which is a challenging subject. Although it's quite obvious that power generated from WT is cheaper and cleaner, significant penetration into the grid threatens the dynamic operation of the conventional grid as they can harm the quality and reliability of the grid due to their uncertainty in generated power (Xiao et al., 2015; Asuhaini et al., 2013; Pannel et al., 2013).

Compared with other kinds of wind driven generators, doubly-fed induction generator (DFIG) has a lower cost and a smaller size due to its low-capacity back-to-back power converters, therefore DFIGs have become popular and are widely deployed nowadays (Rash and Ali, 2017; Zubia et $a l .$, 2012). However, during grid fault, the voltage dip at the point of common coupling (PCC) may seriously affect the stator of the DFIG which is directly connected to the grid, resulting in a transient stator current. Due to the existing magnetic coupling between the stator and rotor windings, high voltage and a large 
transient current in the rotor windings are induced. As a result, the DFIG may be separated from the grid, leading to exaggeration of system failure (Justo and Ro, 2012). At the same time, the power converter switching devices may be damaged due to their low power ratings of the switching devices. More details about the effects of sudden drop of the PCC voltage are illustrated elsewhere (Justo et al., 2015; Justo et al., 2017).

Moreover, the transient effect leads to an increase in the reactive power demand of the induction generator drawn from the grid. Again, the generated over-current may cause severe damage to the semiconductor devices in the rotor side converter (RSC) and large fluctuations of the dc-link voltage. On the other hand, if unbalance faults occur such as two-phase to ground fault and not taken seriously by the system, there will be high unbalance in the stator current with a small amount of disturbance in the stator voltage. The unbalanced currents in the windings can create unequal heating as well as torque and power pulsations in the generator (Ouyang and Xiong, 2014; Justo et al., 2015; Justo et al., 2017). With such conditions, necessary actions are taken in the field of DFIG-based wind turbine systems to prevent or reduce the fault aggravation. However, due to ongoing improvements in the grid code requirements in several countries, specific strategy required to be taken to protect DFIG during faults i.e., fault ride through (FRT) strategy still remain an open problem.
Owning to the facts that the future energy systems is anticipated to integrate several new power system technologies such as: i) demand side management (DSM), ii) information and communication technology (ICT), iii) smart meters' infrastructure, creating an internet dependent energy system and hence several strictly operating requirements (i.e., grid-codes) have been put forward. Such requirements must be fulfilled with any RER connected into the grid such as WTs. In fact, these connections agreement sets out specific technical requirements to be fulfilled by the wind turbines operators as in (Justo and Ro, 2012; Okedu et al., 2012) such as:

- Low of high voltage fault ride through capability, outlining fault duration, fault types, permissible changes to post fault power.

- Frequency range, with time durations for extreme conditions, permissible power reduction at frequency extremes, if any.

- Controllability of the output power, e.g. automatic frequency control, including speed of response.

- Reactive power operating range, e.g. the wind farm to be able to operate with a specified power factor;

- Voltage control capability, etc.

Figure 1 shows the typical grid-code requirements for wind turbines connected to the grid. It states that, 0.2 p.u. or higher of the PCC voltage during fault duration should remain for at least $100 \mathrm{~ms}$. Thereafter, the voltage should rise to $90 \%$ within $525 \mathrm{~ms}$ after fault clearance. 


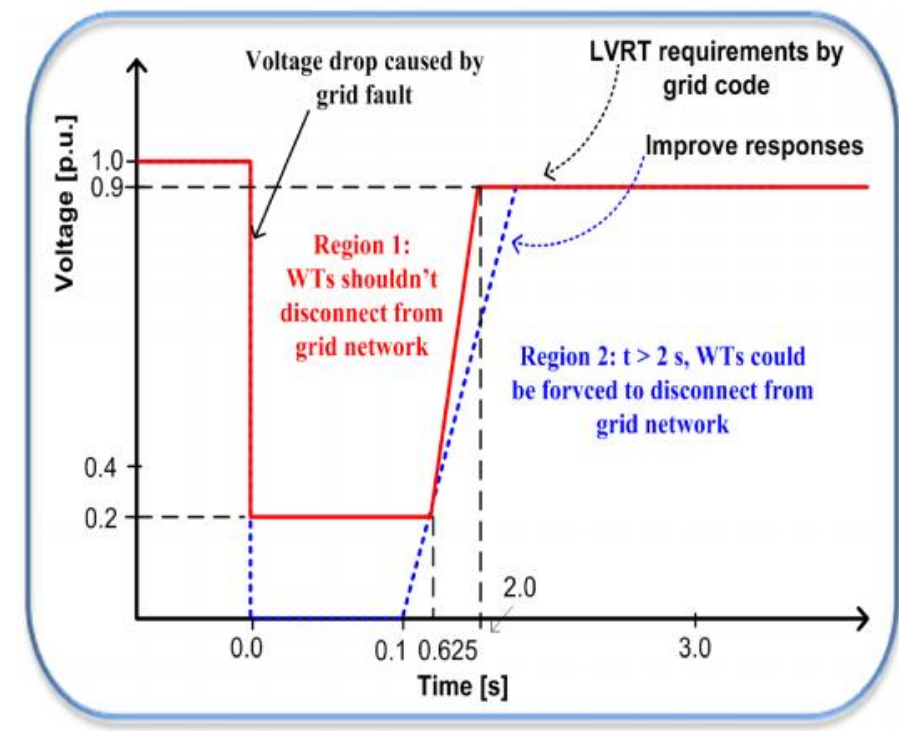

Figure 1: Typical grid-code requirement for LVRT of grid integration wind turbine

To achieve the technical requirements stated above, the crowbar circuits in the rotor side are used to bypass the overcurrent during fault. Although the method is cheap and simple in terms of its switching control, it is incapable of providing the much needed reactive power requirement during fault. This is due to the fact that it operates by short-circuiting the rotor winding to form a squirrel case induction generator (SCIG) configuration (Justo et al., 2015; Okedu et al., 2012). Alternatively, high reactive power requirement during fault may be provided by VAR compensator devices like STATCOM (Justo et al., 2015). However, the presence of these devices increase the overall cost of the system.

In the literature, various improved LVRT strategies of the DFIG to restrain the rotor over current, reduce the dc-link voltage as well as to achieve the LVRT during grid faults have been presented. These protection strategies include installation of extra protection circuits and modification of the control strategies or using advanced control strategies (Xu et al., 2006; Dicorato et al., 2012; Justo et al., 2014). For instance, a crowbar circuit with a dc chopper circuit can be used to limit the rotor current and dc bus voltage (Justo, 2014). Also Sun et al. (2016) and Tohidi and Mohammad-ivatloo (2016) presented a series dynamic resistor integrated with the conventional crowbar circuit to avoid deactivation of the RSC. Moreover, Kong et al. (2014) presented the idea of directly controlling the negative sequence components of rotor current by using multiple proportional resonant (PR) controllers by avoiding the need of notch filters. However, the tuning of the PI controller and using the PR controllers make the overall system more complex.

Therefore, this paper proposes a new LVRT configuration which comprise of a capacitor connected in series with an inductor both connected in parallel to a resistor to improve the capability of DFIG to ride through during fault conditions. This configuration is then connected to the ac side of the rotor side converter (RSC) via a small series resistor unlike the conventional crowbar circuit which has only resistors and blocks the RSC operation when activated. More specifically, the proposed scheme is designed to maintain the RSC connection to the terminals of rotor windings during fault conditions to enhance power supply to the loads. The capacitor in the protection circuit eliminates ripples generated in the rotor voltage while the inductor reduces the current ripple and 
protects the converter switching devices as well as the dc-link capacitor. The overall objectives of the proposed LVRT approach are: to minimize the magnitude of rotor fault currents, maintain a constant dc-link voltage, reduce in crowbar operation time to avoid disconnection between the rotor windings and the RSC, and to enhance the short circuit response of terminal voltage and overall improved dynamic responses of the DFIG wind farm.

Thus, in order to evaluate the performance of the wind turbine, a 1.7 MVA DFIG wind turbine was considered and simulated under symmetrical fault conditions and later a case study of wind farm with 15 MW capacity was investigated on its ability to support the PCC voltage through the supply of extra reactive power. The study was conducted under the proposed and conventional LVRT strategies. Based on simulation results obtained in MATLAB/Simulink package, it is observed that there is significant improvement in the transient responses of the DFIG wind turbine compared to when the conventional strategies are deployed.

\section{METHODS AND MATERIALS}

\section{Mathematical modelling of wind turbine equipped with DFIG}

Wind speed $\left(V_{w}\right)$ increases with height above the ground, the calculation of wind speed data at a given height is carried out by applying the following power law equation (1):

$$
\frac{V_{w-h}}{V_{w-r e f}}=\left(\frac{H}{H_{r e f}}\right)^{\gamma}
$$

Where $\gamma$ is the power law exponent, $V_{w-r e f}$ is the reference wind speed measured $(\mathrm{m} / \mathrm{s})$ and $V_{w-h}$ is the wind speed measured $(\mathrm{m} / \mathrm{s})$ at the height $\mathrm{h}(\mathrm{m})$. In wind project, wind speed distribution is a key factor during wind resource assessment of a given site. Various models such as Weibull, Rayleigh, Lognormal, and Gamma are theoretically applied to fit the distribution of wind speed data. Several studies showed that the Weibull distribution model proved to be the best one due to its great flexibility and simplicity (Justo et al., 2015). The general form of Weibull distribution function for wind speed data is given by expression (2).

$$
f\left(V_{w}\right)=\left(\frac{k}{c}\right) \times\left(\frac{V_{w}}{c}\right)^{k-1} \exp \left[-\left(\frac{V_{w}}{c}\right)^{k}\right]
$$

Where $f\left(V_{w}\right)$ is the probability density function of observed wind speed data, and $k$ (which is dimensionless) and $\mathrm{c}(\mathrm{m} / \mathrm{s})$ are the shape and scale parameters, respectively.

The modelled wind speed shown by equations (1) and (2), is passed through the wind turbine blades which are represented by their efficiency of extracting power from the moving air. This efficiency is called the coefficient of aerodynamics $\left(C_{\mathrm{p}}\right)$, which is the function of the tip-speed ratio $(\lambda)$ and the pitch angle $(\beta)$ of the blades i.e., $\mathrm{C}_{\mathrm{p}}(\lambda, \beta)$. Therefore, the mechanical power, $P_{m}$ extracted by the WT blades is given by equation (3).

$P_{m}=\frac{1}{2} \rho A V_{w}^{3} C_{p}(\beta, \lambda)$

Where $\rho$ is the air density, $A$ is the area swept by WT blades, $\mathrm{V}_{\mathrm{w}}$ is the wind speed, $\mathrm{C}_{\mathrm{p}}(\lambda, \beta)$ is given by equation (4), while the tip-speed ratio, $\lambda$ is given by equation (5):

$$
\begin{aligned}
& C_{P}(\lambda, \beta)=0.22\left(\frac{116}{\lambda_{i}}-0.4 \beta-5\right) e^{\left(-12.5 / \lambda_{i}\right)} . \\
& \lambda=\frac{\omega_{\mathrm{T}} \times \mathrm{R}_{\mathrm{T}}}{\mathrm{V}_{\mathrm{w}}}
\end{aligned}
$$

\section{DFIG modelling and system description}

Figure 2 presents the conceptual diagram of the wind turbine equipped with DFIG. For grid-connected DFIG based WT, the rotor winding terminals are connected to the PCC via the AC/DC/AC power converters while the stator winding terminals are directly connected to the PCC. Depending on the available wind speed, the total power $P_{T}=P_{S}+P_{g}$ and $Q_{T}$ 
$=Q_{s}+Q_{g}$ is delivered to the PCC through the stator and rotor circuits during which the rotor speed $\left(\omega_{r}\right)$ is greater than synchronous speed $\left(\omega_{s}\right)$ i.e., $\omega_{r}>\omega_{s}$. For $\omega_{r}$ $<\omega_{s}$, only the stator circuit transfers the active power $\left(P_{s}\right)$ to the PCC via the stator circuit, meanwhile the rotor circuit absorbs active power $\left(P_{r}\right)$ from the PCC via the $\mathrm{AC} / \mathrm{DC} / \mathrm{AC}$ power converters (Xu et al., 2006; Okedu et al., 2012; Ouyang and Xiong, 2014).
Considering the control requirements and compensation scheme for the DFIG system, if vector control is adopted then the synchronous $d-q$ stator reference frame (SRF) is usually selected to model the DFIG based on $5^{\text {th }}$ order $d-q$ axis representation. The details for the mathematical modelling of the wind turbine equipped with DFIG is documented elsewhere (Kong et al., 2014; Sharma and Bansal, 2017).

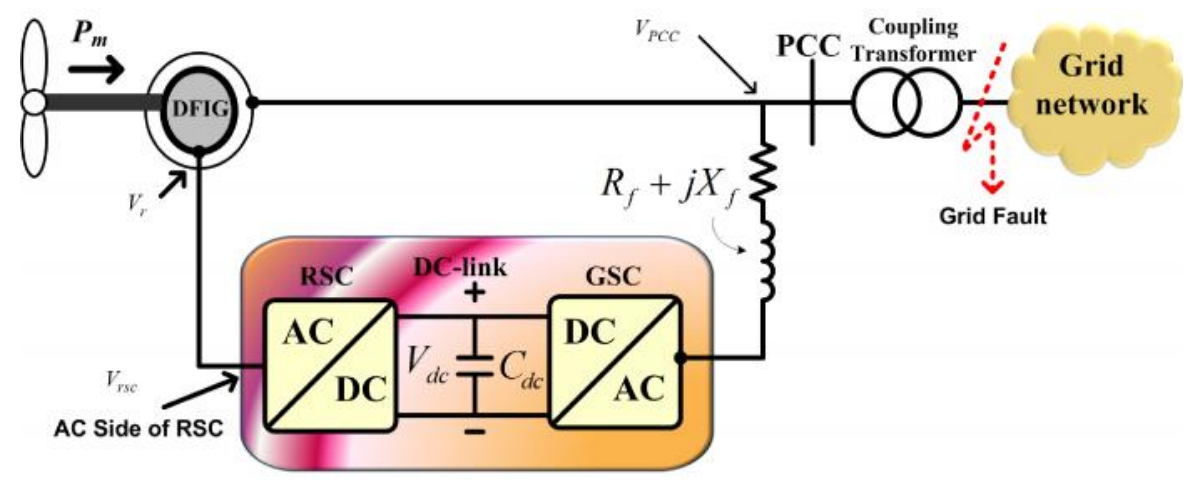

Figure 2: Typical configuration of wind turbine equipped with DFIG

\section{DFIG Control strategies}

To achieve a steady-state operation of the wind turbine equipped with DFIG, the RSC controller is usually designed to $P_{s}$ and $Q_{s}$ by regulating the $q$ - and $d$-axis rotor currents $\left(i_{q r}\right.$ and $\left.i_{d r}\right)$, respectively. In this case, the $P_{s}$ reference is obtained from a look-up table (provided by the wind plant operator) representing the maximum power point tracking (MPPT) algorithm (Justo et al., 2017). Meanwhile, grid-side converter (GSC) controller operates in a grid ac voltage reference frame (GCVRF) and regulates the dc-link voltage $\left(V_{D C}\right)$ and the reactive power $\left(Q_{g}\right)$ exchange with the PCC regardless of the direction of the rotor power flow. It operates in synchronism with the ac voltage whereby a built-in model of a phased-locked loop $(P L L)$ is used to determine the voltage angle (Ouyang and Xiong, 2014). In this study, Non-windup proportional integral (PI) controllers are used to define the rotor current and voltage set-points and rotor voltages, $V_{r}$, are applied by defining the modulation index as shown by equation (6):

Modulation Index $=2 \sqrt{2 V}_{r} / \sqrt{3 V_{D C}}$

Where $V_{D C}$ is the dc link voltage.

Now, following the increase in penetration of wind turbines in the grid network over the last decade, grid codes require that these generators have to contribute with the power system stability. And researchers involved with WTs equipped with DFIG are still much more concerned about their influence into the grid and impacts of disturbances on DFIGs. In fact, it is important to consider the facts that, during grid faults, these WTs are more vulnerable to disturbances when one or more phase voltages at the PCC suddenly drop close to zero result in a large transient current at the stator terminals (Okedu et al., 2012; Ouyang and Xiong, 2014).

\section{Low voltage ride through strategies}

$\mathrm{R}$-crowbar protection circuit is a set of parallel-connected resistors installed at the 
slip-rings of the DFIG i.e., between rotor windings terminals and ac-side of the RSC. When a fault is detected, the switching control engages the $R$-crowbar by short circuiting the generator rotor through its resistor $\left(R_{c r w}\right)$, see Figure 3. In this case, the power converter is temporarily blocked and the generator excitation control is usually lost ( $\mathrm{Xu}$ et al., 2006). This resulting mode of operation leads to the DFIG being transformed into the tradition induction machine i.e., squirrel-cage induction generator (SCIG).

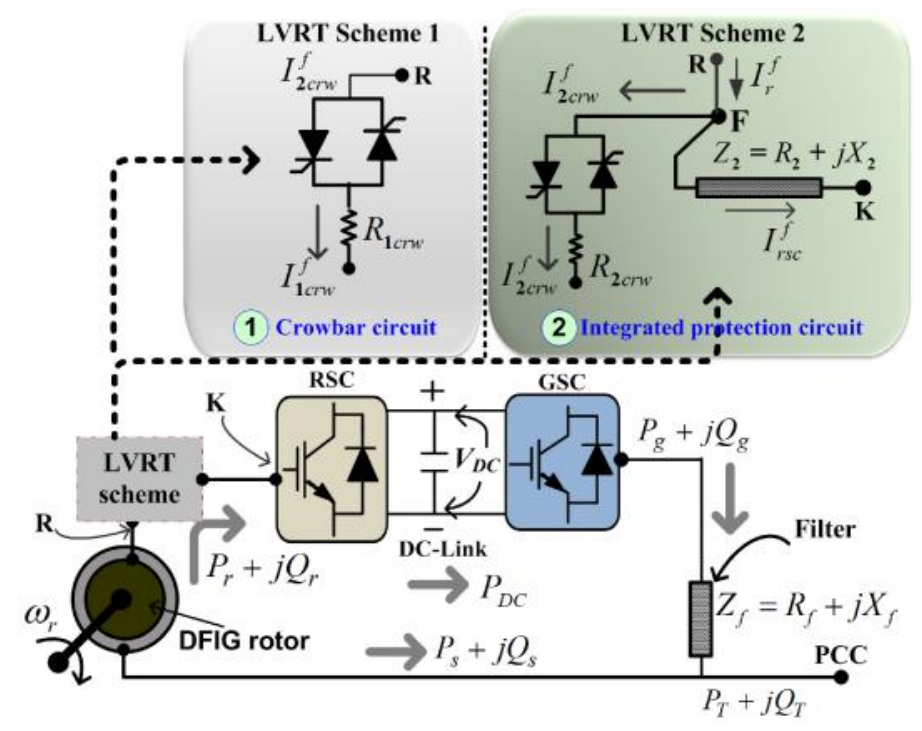

Figure 3: Conventional crowbar (R-crowbar) protection circuit configuration for DFIG wind turbine

The SCIG temporary operating characteristics are noticed by its behaviour of high rate of drawing reactive currents from the grid via the generator stator that supports the generator magnetization process. As a result of such scenario, a further decrease of network voltage at the PCC which in turn may lead to a failure to comply with the grid-code requirements. This limitations of the crowbar protection circuit, improved configuration of crowbar protection scheme i.e., crowbar integrated with series $R-L$ circuit is presented in (Justo et al., 2012; 2014; and 2015). In that case, the SCIG features are minimized by the facts that, disconnection of RSC from rotor windings terminals is avoided during grid faults. However, current and torque ripples are still a problem to be solved.

\section{Proposed protection circuit}

To reduce the negative effects of the crowbar circuit, an improved version i.e., integrated circuit combining the $R$-crowbar in parallel with $L-C$ circuit both of which are connected to ac-side of RSC via a small resistor. The circuit is installed in a similar way as crowbar between the rotor windings with the ac-side terminals of the RSC being connected to the terminals of rotor windings via the series resistor branch during fault as indicated in Figure 4. It is well known that, during grid disturbance, the inrush rotor current increases more than its threshold value (i.e., $\left.I_{r}>I_{r t h}\right)$ where, $I_{r t h}=2.0$ p.u. In that case, it is installed to bypass the transient rotor current through it connected between the rotor winding terminals and ac-side terminals of the RSC.

Neglecting the switching transients of the circuit, it can be said that when the proposed protection circuit is applied, the RSC connection to the rotor winding terminals is maintained compared to when only crowbar circuit is applied. In that 
case, its excitation control is also maintained since the generator is partly grounded via the $R / L-C$ crowbar and partly connected to the RSC through the series resistor branch. Alternatively, this operating phenomenon transforms the DFIG characteristics into a temporary state in which the induction machine behaves partially as the wound rotor induction generator because of being partly connected to the RSC via the resistor Rseries branch and literally operates as SCIG following its partly short-circuiting of the rotor windings through the crowbar circuit. To easily explain the concept of transformation between SCIG and DFIG, let $\lambda$ (with value lying between 0 and 1 ) be an index representing the features of DFIG at any particular operating point. During normal and transient without protection circuit operation, $\lambda_{d}=1$ while during transient with $R$-crowbar circuit, $\lambda_{\mathrm{d}}=0$. Meanwhile, the proposed protection have an index with value in the region $0<\lambda \leq 1$ i.e., if DFIG features has $\lambda_{\mathrm{d}}=\mathrm{m}$ and SCIG has $\lambda_{s}=n$ then $\lambda_{d}>\lambda_{s}$. Thus, depending on the proposed protection circuit parameters, the integrated protection circuit behaves as presented in Table 1.

Table 1: Summary of DFIG transformation into SCIG

\begin{tabular}{|c|l|c|c|l|}
\hline S/N & \multicolumn{1}{|c|}{ Protection circuit approach } & $\begin{array}{c}\text { DFIG } \\
\text { Features }\end{array}$ & $\begin{array}{c}\text { SCIG } \\
\text { Features }\end{array}$ & \multicolumn{1}{|c|}{ Reference } \\
\hline 1 & Without any protection circuit & $\lambda_{\mathrm{d}}=1$ & $\lambda_{\mathrm{s}}=0$ & \\
\hline 2 & $R$-crowbar & $\lambda_{\mathrm{d}}=0$ & $\lambda_{\mathrm{s}}=1$ & Justo and Ro (2012) \\
\hline 3 & $R$-crowbar + dc-link chopper & $\lambda_{\mathrm{d}}=0$ & $\lambda_{\mathrm{s}}=1$ & Justo et al. (2015) \\
\hline 4 & $R$ - $L$ crowbar + series resistance & $\lambda_{\mathrm{d}} \neq 0$ or 1 & $\lambda_{\mathrm{s}} \neq 1$ or 0 & $\begin{array}{l}\text { Tohidi and } \\
\text { Mohammad-ivatloo } \\
(2016)\end{array}$ \\
\hline 5 & Proposed $R / L-C+$ series resistance & $\lambda_{\mathrm{d}} \neq 0$ or 1 & $\lambda_{\mathrm{s}} \neq 0$ or 1 & \\
\hline
\end{tabular}

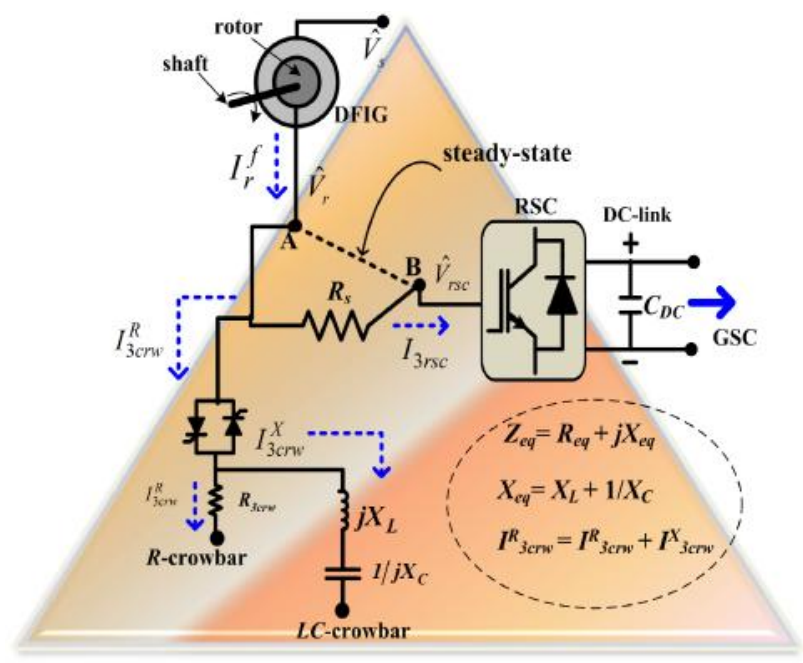

Figure 4: Proposed protection circuit configuration for DFIG wind turbine

\section{RESULTS AND DICUSSION}

To verify the performance of the proposed protection circuit, extensive simulation studies are conducted using MATLAB/Simulink package for a 1.5 MW DFIG based WT with and without the protection circuits. In this study, conventional crowbar protection circuit and crowbar integrated with series $R-L$ protection circuits are considered for simulation and comparative study. Now, for simplicity purposes and considering the facts that grid faults are of short duration, then the following assumptions are taken during modelling process and simulation studies:

i) mechanical time constant $\left(T_{m}\right)$ of the wind turbine blades is assumed to be larger than that of the generator $\left(T_{g}\right)$, 
ii) wind speed variations between fault occurrence and fault clearance are neglected.

To ensure the continuous safe operation of the power converters and dc-link capacitor, the converter current $\left(I_{r s c}\right)$, dc-voltage $\left(V_{D C}\right)$, modulation index for the converters are investigated. Lastly, parameters values of the protection circuit are selected through extensive simulation studies while considering the limitations of both RSC switching devices and dc-link capacitor and the ON/OFF period of the power electronics switching devices used for the protection circuits is assumed to be negligible.

\section{Steady-state responses}

During steady-state performance with the rated wind speed $V_{w}=12 \mathrm{~m} / \mathrm{s}$, the response of the current into the RSC, $I_{r s c}=I_{r}$, rotor voltage, dc link voltage, $V_{D C}$ and PWM index are presented for simulation time of 12 s. In this case, the rated (nominal) values of $I_{r s c-N o m}=I_{r}=1.77 \mathrm{kA}, V_{D C-N o m}=$ $1.2 \mathrm{kV}$, rms values of $V_{r}=0.8 \mathrm{kV}$, and Modulation index, $M=0.67$. It is to see that the selected parameters are maintained at their desired values.

\section{Transient-state responses: balanced 3- phase fault}

To validate the performances of the protection circuits, a severe 3-phase balanced grid-fault condition was considered, which was initiated at $\mathrm{t}=7.5 \mathrm{~s}$ and cleared at $\mathrm{t}=7.65 \mathrm{~s}$. It was initiated at $3 \mathrm{~km}$ from the PCC leading to a voltage dip with magnitude of the more than $85 \%$ at the PCC. Simulation results obtained from extensive simulation studies are presented by first comparing four waveforms of four different DFIG parameters which are shown below. In i) Figure 5 shows the responses under fault without any protection circuit, ii) in Figure 6 indicates the responses under fault with and without conventional crowbar protection circuit, and iii) Figure 7 depicts the responses under fault with and without proposed protection circuit. Examining the waveforms shown by the red solid-lines on Figure 5 under fault without activation of protection circuit, the peak value of inrush current rises to above $5.5 \mathrm{kA}$ (more than $200 \%$ increase). This is higher than its threshold value which in this case $I_{r s c}$ ${ }_{t h}=3.54 \mathrm{kA}$ (i.e. $I_{r s c-t h}=2 I_{r s c-\mathrm{Nom}}$ ) immediately after the occurrence of fault initiation. This indicates a serious threat to the power electronics devices which have low rating for DFIG configuration. Moreover, $V_{D C}$ response shoots to above $1.95 \mathrm{kV}$ indicating a danger to the dc-link capacitor while the rotor voltage oscillates and immediately stabilize after fault clearance. In the case of modulation index, due to dip in PCC voltage, which leads to a dip in rotor voltage, the direct relationship between these parameters leads to decrease to a minimum value of 0.2 at $\mathrm{t}=7.65 \mathrm{~s}$.

However, Figure 5 shows the comparative results when the conventional crowbar protection circuit is engaged and when not engaged. In that case, the inrush current is reduced to zero i.e. $I_{r s c} \approx 0 \mathrm{kA}$, at time 7.53 $\mathrm{s}$, which indicates that the RSC operation is temporary disabled regardless of the continuous operation of the generator. The dc link voltage is also reduced from $1.9 \mathrm{kV}$ to $1.19 \mathrm{kA}$ as its maximum value. Although these oscillations are within the safe operating area (SOA) as the maxima value is less than 1.35 p.u., they indicate that the transfer of power between the dclink and the PCC is seriously affected due to deactivation of the RSC. Also, the modulation index is maintained within its pre-fault value although it significantly oscillates with its minimum value of 0.44 occurring $14 \mathrm{~ms}$ after the fault initiation.

Considering the responses under fault with the proposed protection circuit shown in Figure 6, the high currents are of $5.5 \mathrm{kA}$ 
instantly damped through the $R / / L-C$ impedance crowbar with the peak value reduced to $3.5 \mathrm{kA}$ and oscillates to lower value of $0.81 \mathrm{kA}$ followed by smooth responses. Moreover, the dc-link voltage oscillates between $1.35 \mathrm{kV}$ (peak value) and $0.99 \mathrm{kV}$ (lower value). On the other hand, with the proposed protection circuit, the minimum value of modulation index is 0.41 occurring at $7.64 \mathrm{~s}$.
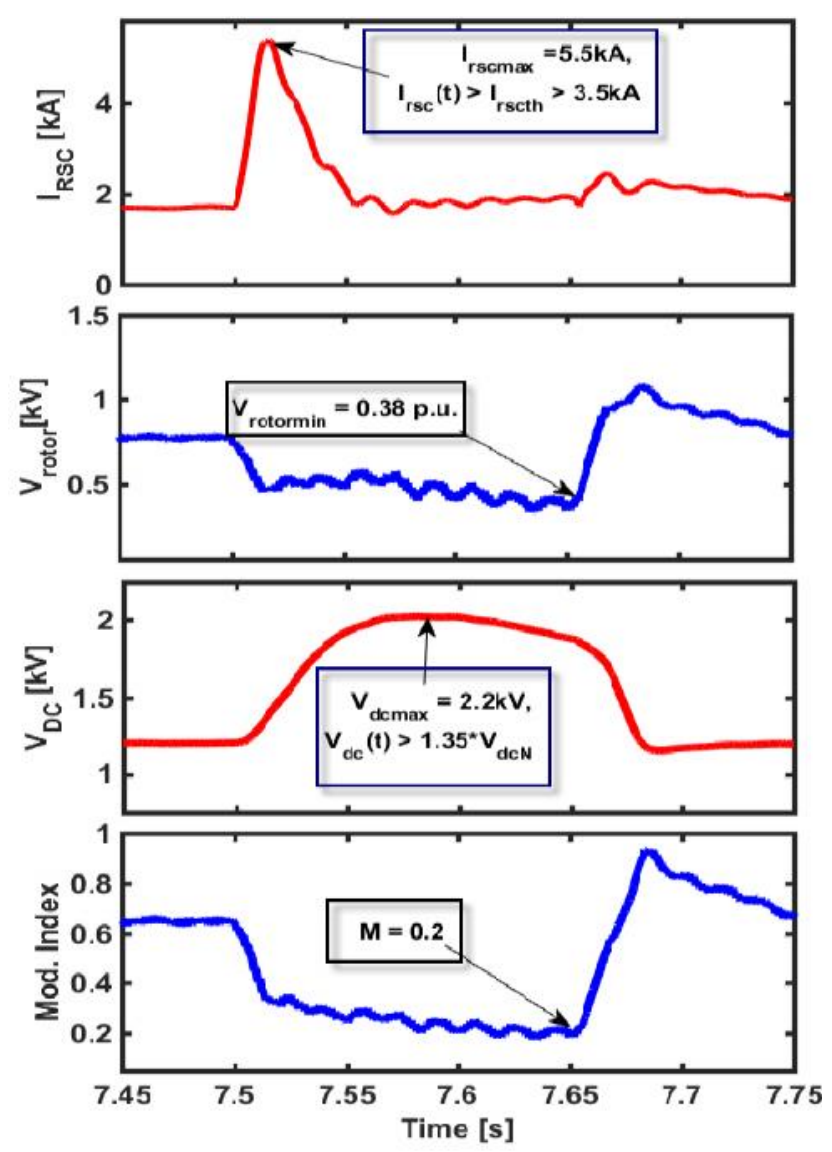

Figure 5: Transient response of the DFIG wind turbine under 3-phase short circuit condition: converter currents $\left(I_{r s c}\right)$, rotor voltage, dc-link voltage $\left(V_{D C}\right)$, and modulation index
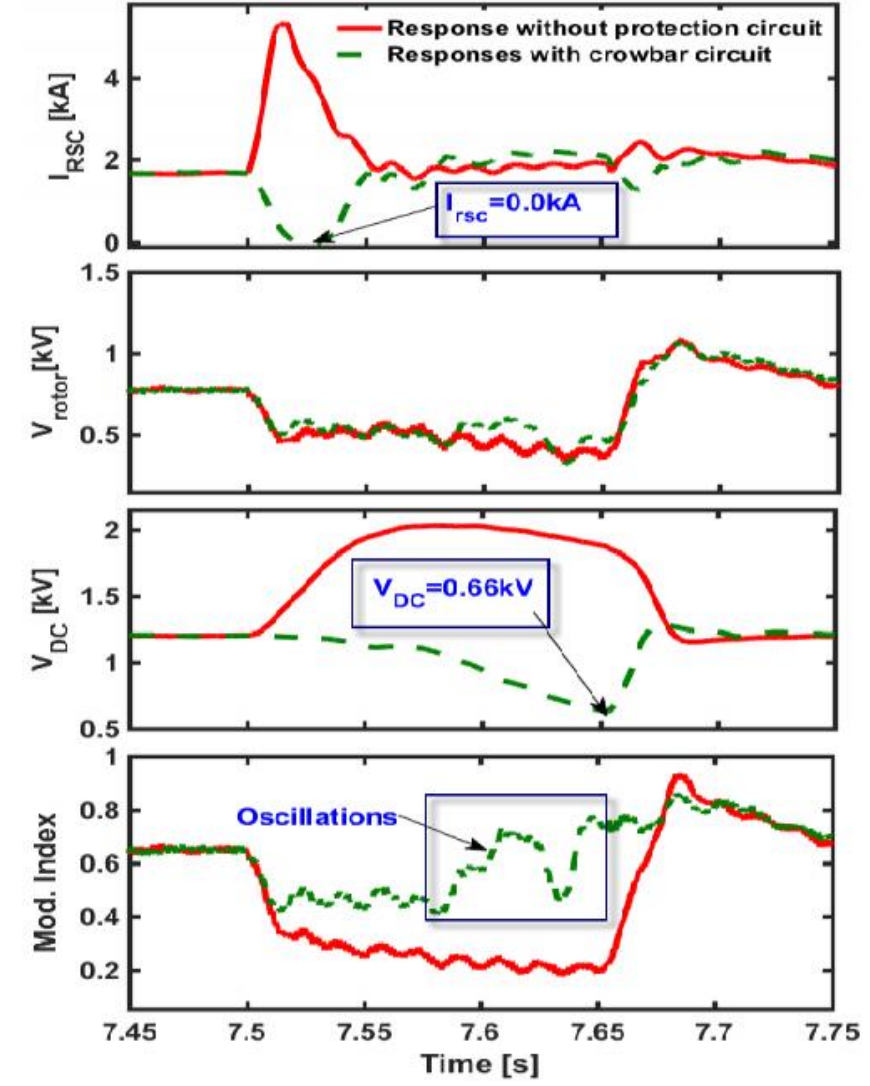

Figure 6: Transient response of the DFIG wind turbine under 3-phase short circuit condition with and without crowbar circuit: converter currents $\left(I_{r s c}\right)$, rotor voltage, dc-link voltage $\left(V_{D C}\right)$, and modulation index

These responses under the proposed protection circuit indicate that the DFIG excitation control is well maintained and hence improved responses during transient state are achieved. On the other hand, the presence of series $L-C$ elements in the crowbar branch helps to improve the current absorbed, which could not be the case of only crowbar with series $R-L$ protection circuit. It means that, the $R / / L-C$ crowbar branch with the new introduced capacitance parameter effectively compensates the fluctuation of the current to the ac-side of the RSC. 

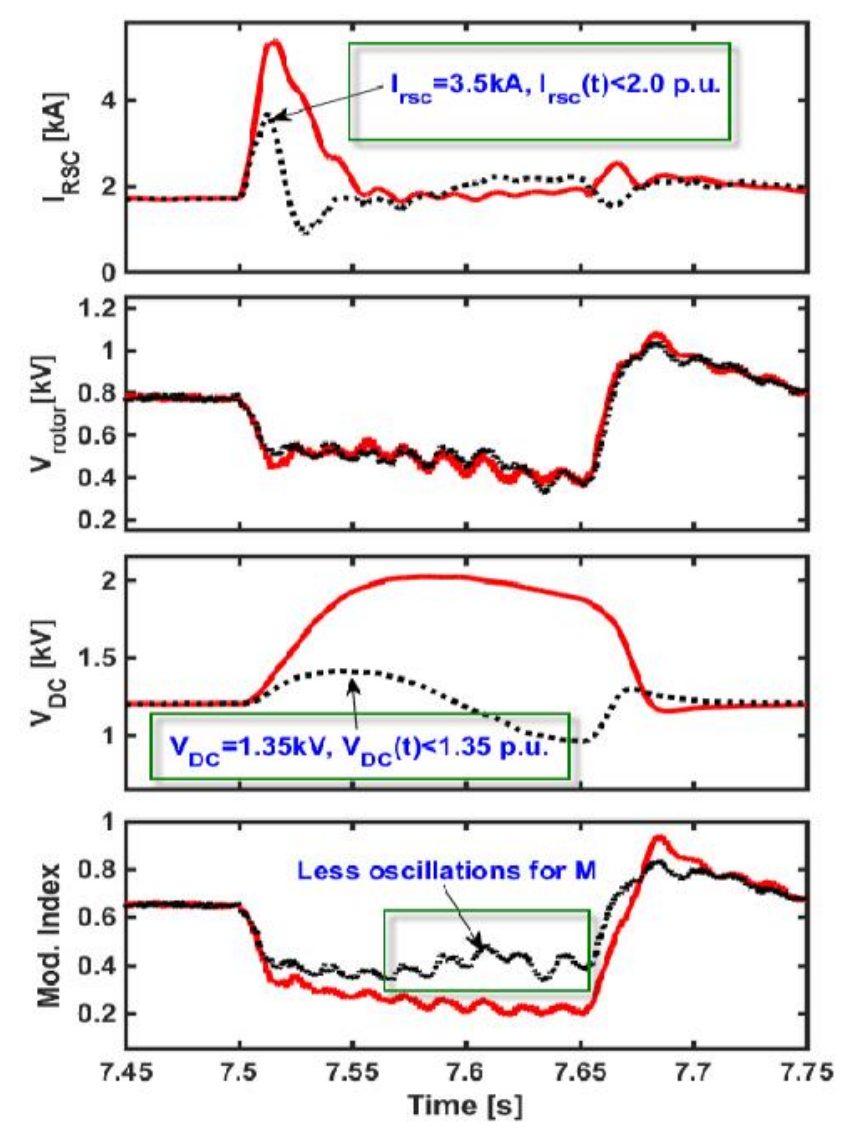

Figure 7: Transient response of the DFIG wind turbine under 3-phase short circuit condition with and without proposed protection circuit: converter currents $\left(I_{r s c}\right)$, rotor voltage, dc-link voltage $\left(V_{D C}\right)$, and modulation index

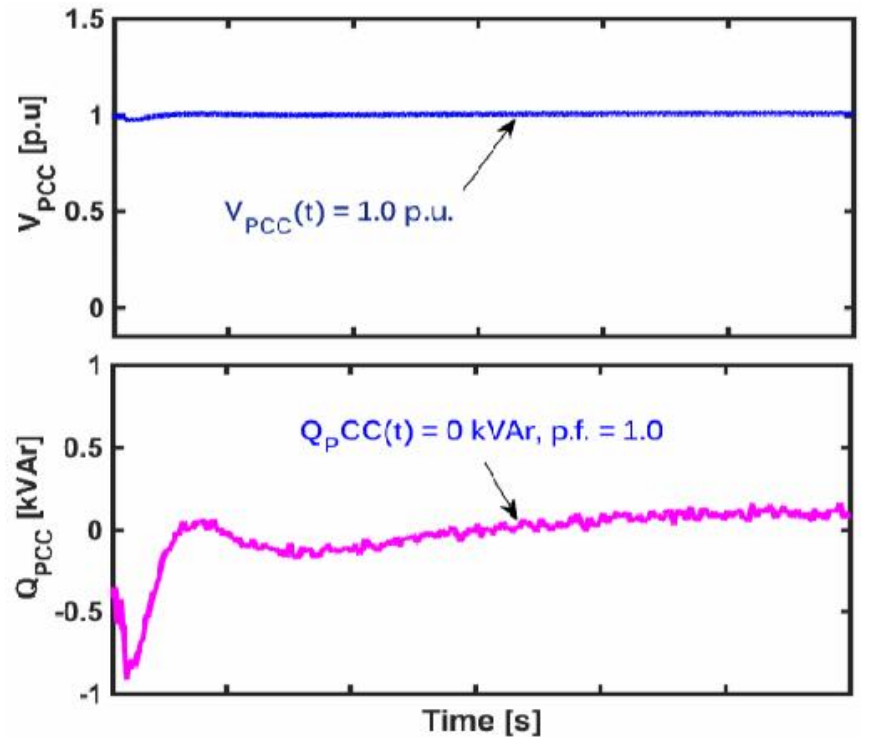

(a)
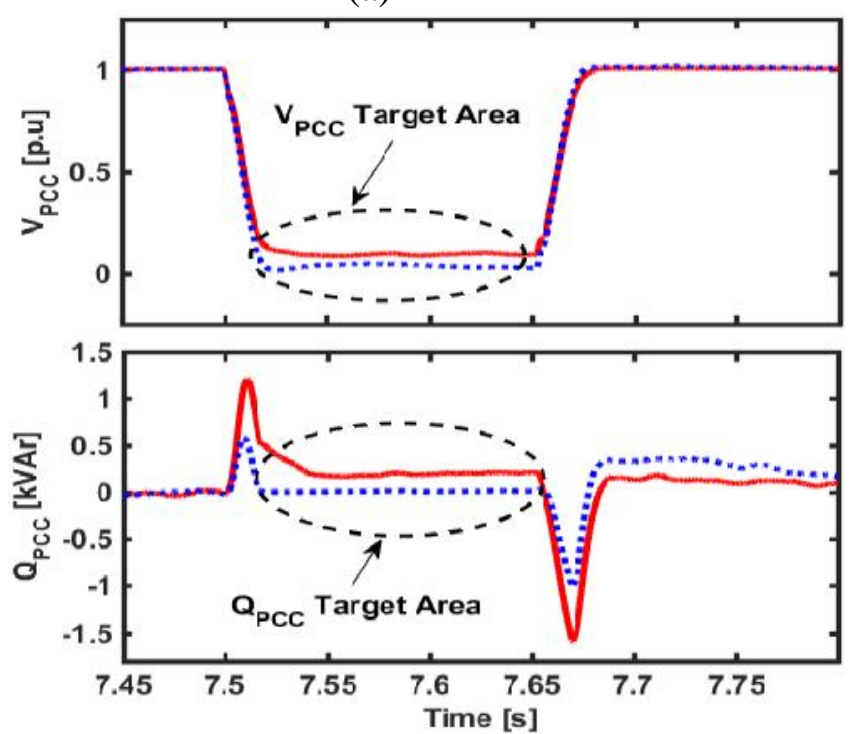

(b)

Figure 8: Responses of the DFIG wind turbine under: (a) Steady-state and (b) Three-phase fault condition with (dotted line) and without (solid line) crowbar protection

Table 2: Summary of comparative response between conventional and proposed LVRT strategies

\begin{tabular}{|l|l|l|}
\hline \multicolumn{1}{|c|}{ Circuit } & Conventional LVRT circuit & Proposed LVRT circuit \\
\hline Parameter & $I_{r s c}=0 \mathrm{kA}$ & $I_{r s c}=3.5 \mathrm{kA}$ \\
\hline DC link voltage & $V_{D C}=1.19 \mathrm{kA}$ & $V_{D C}=1.35 \mathrm{kV}$ \\
\hline Modulation index & $M_{\text {index }}=0.44$ & $M_{\text {index }}=0.41$ \\
\hline
\end{tabular}


Figure 9 indicates the reactive power support supplied by the wind farms at the point common coupling (PCC) with the grid. It can shown that in Figure 9(a), wind turbines supports very small amount of reactive power collectively without modified control to support the highly needed reactive power at the PCC. Meanwhile, with the modified controller, the $Q_{\text {PCC }}$ support improves and hence $V_{\text {PCC }}$ profile is improved. This means that the DFIG wind farm can also participate to support the grid voltage during grid disturbance without jeopardizing its profile.

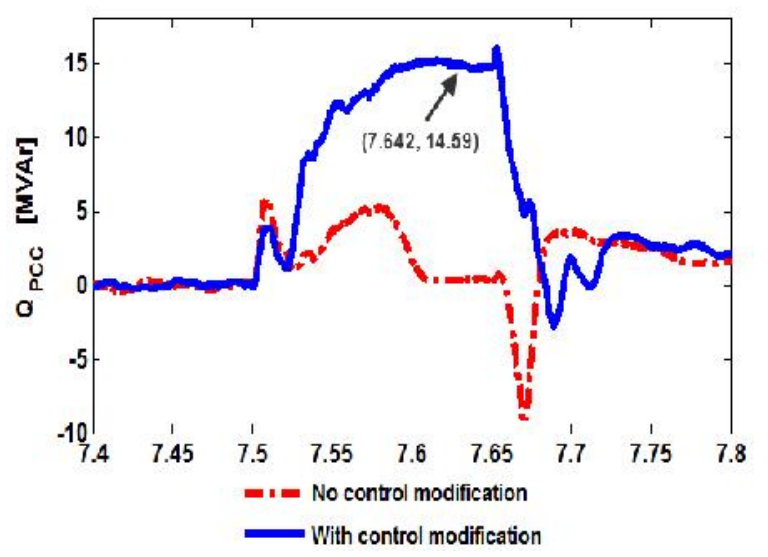

(a)

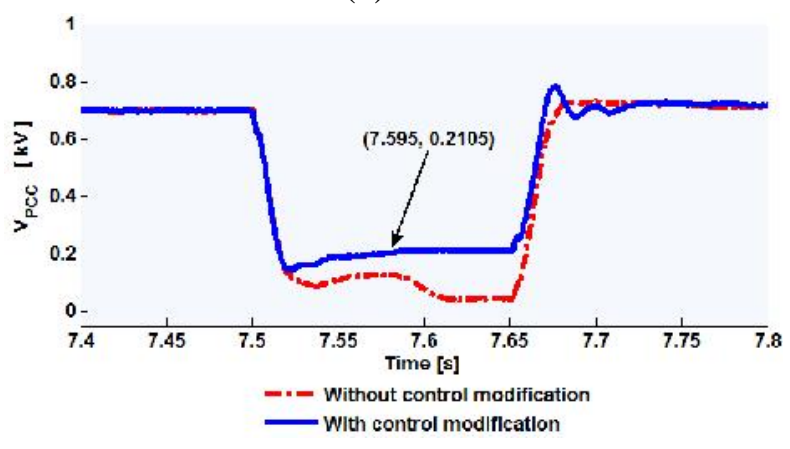

(b)

Figure 9: Comparative responses of the 15 DFIG wind farm: (a) PCC reactive power support and (b) PCC voltage profile.

\section{CONCLUSIONS AND RECOMMENDATIONS}

This paper proposed a low voltage ride through (LVRT) scheme to enhance the fault ride-through capability of the DFIG based WTs during transient-state. The performance comparison between the proposed and conventional LVRT schemes was carried out through simulation results and analysis. It was shown that by employing the proposed LVRT scheme, additional hardware to the DFIG based WTs was avoided. As a result, the system reliability as well as the efficiency was highly improved. The effectiveness of the proposed scheme was verified via MATLAB/Simulink software and the results were compared with those of the conventional schemes for the rotor overcurrent and dc-link overvoltage responses. It was found out that the proposed LVRT scheme could provide good transient responses by avoiding the loss of power control unlike the conventional LVRT schemes. In fact, with the proposed LVRT scheme the reactive power support can easily be enhanced to support the terminal voltage as per most grid-code requirements. Also, the wind farm consisting of the DFIG based WTs contributed more to the PCC voltage regulation when equipped with the proposed scheme than with the conventional schemes (the crowbar and combined schemes).

\section{REFERENCES}

Asuhaini B., Zin B.M., Pesaran M.H.A. and Khairuddin A.B. (2013). An overview on doubly fed induction generators control and contributions to wind based electricity generation, Renew. Sustain. Energy Rev., 27: 692-708.

Dicorato M., Forte G. and Trovato M. (2012). Wind farm stability analysis in the presence of variable-speed generators, Energy, 39(1): 40-47.

Justo J.J. and Ro K.S. (2012). Control strategies of doubly fed induction generator based wind turbine system with new rotor current protection topology, J. Renew. Sustain. Energy, 
4(4):043123.

https://doi.org/10.1063/1.4748808.

Justo J.J., Mwasilu F. and Jung J.W. (2014). Doubly-fed induction generator wind turbines: A novel integrated protection circuit for lowvoltage ride-through strategy, $J$. Renew. Sustain. Energy, 6(5): 053129.

Justo J.J., Mwasilu F. and Jung J.W. (2015). Doubly-fed induction based wind turbines: A comprehensive review of fault ride-through strategy, Renew. Sustain. Energy Rev., 45: 447-467.

Justo J.J., Mwasilu F. and Jung J.W. (2017). Enhanced crowbarless FRT strategy for DFIG based wind turbines under three-phase voltage dip, Electr. Power Syst. Res., 142: 215-226.

Kong X., Xianggen Z.Z. and Wen M. (2014). Study of fault current characteristics of the DFIG considering dynamic response of the RSC, IEEE Trans. Energy Convers., 29(2): 278-287.

Okedu K.E., Muyeen S.M., Takahashi R. and Tamura J. (2012). Wind farm fault ride through using DFIG with new protection scheme, IEEE Trans. Sustain. Energy, 3(2): 242-254.

Ouyang J. and Xiong X. (2014). Dynamic behavior of the excitation circuit of a doubly-fed induction generator under a symmetrical voltage drop, Renew. Energy, 71: 629-638.

Pannel G., Zahawi B., Atkinson D.J. and Missailidis P. (2013). Evaluation of the performance of a dc-link brake chopper as a DFIG low-voltage faultride-through device, IEEE Trans. Energy Convers., 28(3): 535-542.
Rash G. and Ali M.H. (2017). Fault ride through capability improvement of DFIG based wind farm by fuzzy controlled parallel resonance fault current limiter, Electr. Power Syst. Res., 146: 1-8.

Sharma G. and Bansal, R.C, (2017). DFIG Based AGC of Power System Using Robust Methodology, Energy Procedia, 105: 590-595.

Sun P., Li J., Wang C. and Lei X. (2016). A generalized model for wind turbine anomaly identification based on SCADA data, Appl. Energy, 168: 550-567.

Tohidi S. and Mohammad-ivatloo B. (2016). A comprehensive review of low voltage ride through of doubly fed induction wind generators, Renew. Sustain. Energy Rev., 57: 412-419.

Xiao F., Zhang Z. and Yin X. (2015). Fault current characteristics of the DFIG under asymmetrical fault conditions, Energies, 8: 10971-10992.

$\mathrm{Xu}$ L., Yao L. and Sasse C. (2006). Comparison of using SVC and STATCOM for wind farm integration, Proc. IEEE, International Conference on Power System Technology, Chongqing, China.

Zubia I., Ostolaza J.X., Susperregui A. and Ugartemendia J.J. (2012). Multimachine transient modeling of wind farms: An essential approach to the study of fault conditions in the distribution network, Appl. Energy, 89(1): 421-429. 